\title{
RADIO ASTRONOMY AT WARC MOB-87
}

\author{
T. E. GERGELY
}

National Science Foundation, Division of Astronomical Sciences 1800 G Street, N.W., Washington, D.C., 20550 U.S.A.

\begin{abstract}
The World Administrative Radio Conference for the Mobile Services (WARC Mob-87), held in Geneva in September-October, 1987 , took several actions that will have an impact on radio astronomy. Worldwide frequency allocations were made for the Radiodetermination Satellite Service (RDSS) in the 1610 to $1626.5 \mathrm{MHz}$ band. The secondary allocation to radio astronomy in this band has received strong protection, however. The 1660 to $1660.5 \mathrm{MHz}$ band, which radio astronomy shared on a primary basis with the Aeronautical Mobile Satellite Service has been reallocated to the Land Mobile Satellite Service, shared with radio astronomy on a similar basis. The impact that this reallocation will have on radio astronomy is not clear. Since the Radioastronomy Service is primary in the band, Mobile Satellite Systems that evolve will have to provide adequate protection. Perhaps most significantly, WARC Mob-87 recommended that a conference be convened to reallocate all bands in the 1 to $3 \mathrm{GHz}$ range, no later than in 1992 . Several other conferences dealing with particular services have been proposed. At first glance, some of these proposals may not appear to have an impact on radio astronomy. They will, however, increase the pressure on the entire radio spectrum. Finally, it is highly likely that a General WARC will be proposed to be held before the end of the 1990s. The radio astronomy community will have to prepare for these conferences.
\end{abstract}

\section{INTRODUCTION}

The International Telecommunication Union (ITU) is a specialized agency of the United Nations, operating under the ITU convention. Over 170 nations are signatories to the Convention, which spells out the objectives and responsibilities of the organization. The most important of these is to ensure the orderly use of the radio spectrum. The technical agreements related to the use of the spectrum are embodied in the Radio Regulations, published by the ITU. Due to the introduction of new technologies and changing spectrum requirements, as well as other changes, the Radio Regulations are revised periodically through the mechanism of International Radio Conferences, denominated World Administrative Radio Conferences (WARCs). WARCs may be general, dealing with the entire spectrum (or portions of it), or limited to certain radio services or specific topics. For frequency allocation purposes, the world is divided in three Regions. Broadly speaking, Region 1 includes Europe and Africa; Region 2 includes the Americas; and Region 3 includes Asia and 
Australia.

The World Administrative Radio Conference for the Mobile Services 1987 (WARC MOB-87) was convened by the ITU for 5 weeks, beginning September 14,1987 . The Conference was charged with reviewing and revising those provisions of the Radio Regulations which relate to the mobile services, the mobile-satellite services, and the radionavigation and radiodeterminationsatellite services; with examining the requirements for the use of public correspondence by aircraft and making provisions for it, if it was found necessary to do so; and with making consequential changes related to all of the above. The WARC MOB-87 agenda did explicitly include both regulatory and allocations issues.

The Radio Regulations define 37 radio communication services, about a dozen of which are mobile. Approximately two-thirds of the spectrum from 30 $\mathrm{MHz}$ to $15 \mathrm{GHz}$ is allocated to the various mobile services and, therefore, by definition came under the competence of WARC MOB-87. On the other hand, the actions of the Conference were limited by the requirement that they impact only minimally on radio services not specifically included in the Agenda. The Conference, therefore, was not empowered to make changes in the status of passive bands, and radio astronomy concerns were limited to possible changes in those bands which are shared with the mobile services. Due to the requirement of "minimum impact," the Conference could not change the allocation status of the Radio Astronomy Service in shared bands (e.g. from a primary to a secondary allocation) but, by altering the status of a mobile service in some of the shared bands, it had the potential of bringing about a worsening interference situation for radio astronomy.

Concerns were raised by three issues:

1) A primary allocation was proposed for a Radiodetermination Satellite Service (RDSS) uplink in the $1610-1626.5 \mathrm{MHz}$ band. Radio astronomy has a secondary allocation in the 1610.6-1613.8 MHz subband, used for observations of the $1612 \mathrm{MHz}$ OH line.

2) The same band was proposed for development of terrestrial Aeronautical Public Correspondence (APC) systems, the technical term used for telephone service provided from aircraft by means of terrestrial stations (as opposed to provision of the service via satellites).

3) A primary allocation was proposed for the Mobile Satellite Service (MSS) uplink in the $1660-1660.5 \mathrm{MHz}$ band used by radio astronomers to observe the redshifted 1665 and $1667 \mathrm{MHz}$ OH lines.

In addition to these areas of concern, of direct impact on the interference situation experienced by $\mathrm{OH}$ line observers, another could be added:

4) Would WARC MOB-87 issue Resolutions or Recommendations to hold future WARCs and refer allocation decisions to them? In particular, would the Conference call for a General WARC in the $1-3 \mathrm{GHz}$ region of the spectrum, as anticipated?

I will discuss the actions of WARC MOB-87 related to these issues, which have a potential impact on radio astronomy. While I will deal with these issues 
separately, it must be kept in mind that they were interrelated in complex, multiple, and often subtle ways. For example, APC services may be provided via ground stations or via satellites. The member countries of the European Community, collectively referred to as the CEPT countries, preferred (and still do) the former approach while the USA and Canada preferred the later approach and wanted the service to be provided as part of the MSS. The reasons for the difference are many. Demographics, economics, geography, available technology, attitudes toward standardization, and the perceived role of private industry and government all play a part and are interwoven to an almost inextricable degree. To further complicate the matter, providing APC and RDSS Services in the same band may be extremely difficult, and even impossible, due to the characteristics of the systems involved. Further, any country's sentiments in favor of or against holding future WARCs depended heavily on its needs being met at the present Conference. A thread, linking the four issues mentioned, can thus be seen.

Because of the interrelation of the issues, a country's success in achieving its objectives at the Conference often depended on the order in which the issues were discussed, and this order itself frequently became the subject of intense maneuvering. The issues of interest to radio astronomers happened to be among the most contentious ones the Conference had to deal with, and they kept being postponed in the hope that solutions could be found that would satisfy the different countries and participating organizations. In the case of the first two issues (the RDSS allocations and the APC), solutions were reached after extensive negotiations. In the case of the MSS allocations, however, the actions of the Conference, taken only in its final hours, were unsatisfactory to all participants.

\section{RADIODETERMINATION SATELLITE SERVICE (RDSS)}

The function of the RDSS is to provide radiolocation and communication services using satellites. A system that will provide such services is currently being deployed in the U.S., and similar systems are under development in a number of other countries. A general description of RDSS systems has been given by Rothblatt (1987). The U.S. proposal to WARC MOB-87 included worldwide, primary allocations for the RDSS in the bands $1610-1626.5 \mathrm{MHz}$ (Earth-to-space direction) and 2483.5-2500 MHz (space-to-Earth direction) and a footnote allocation in the $5117-5183 \mathrm{MHz}$ band to provide feeder links for the service. The radio astronomy service (RAS) has a secondary allocation in the 1610.6-1613.8 MHz subband (RR 734) for spectral line observations. In the U.S. a coordination procedure, involving time and geographical sharing, was worked out between the Committee on Radio Frequencies (CORF) of the National Academy of Sciences and the Geostar Corporation, a leading company proposing to provide the service. This agreement was subsequently adopted by the Federal Communications Commission (FCC) and imposed on all future providers of the RDSS in the U.S. In order to provide protection to the RAS, and to minimize the impact of the proposed allocation, the U.S. proposals contained a new Recommendation which paralleled the coordination procedure adopted domestically.

The U.S. allocation proposal to the Conference was supported by a large 
number of countries, including some with a radio astronomy community interested in the affected portion of the spectrum (such as Australia, India, and Italy) and a number of developing countries. It was opposed by others, most conspicuously by the United Kingdom (U.K.), the Federal Republic of Germany (FRG), and the Soviet Union (U.S.S.R.). The U.K., the FRG and the U.S.S.R. listed the possible impact of RDSS on radio astronomy as one reason for opposing the allocation.

After lengthy discussions of the sharing criteria and other technical and policy matters, the $1610-1626.5 \mathrm{MHz}$ band was allocated to the RDSS on a shared, primary basis in Region 2 and on a shared, secondary basis in Regions 1 and 3. A large number of countries in Regions 1 and 3 chose, however, to give primary status to the radiodetermination satellite service through a footnote provision (RR 734B). The U.S.S.R., the German Democratic Republic (GDR), and some other socialist countries in Region 1, and Argentina and Cuba in Region 2, chose not to recognize the RDSS allocations at all.

In regions 1 and 3 , strong protection was afforded to the RAS through a footnote (RR 734E), which reads: "In Regions 1 and 3 harmful interference shall not be caused to stations of the radio astronomy service using the band $1610.6-1613.8 \mathrm{MHz}$ by stations of the radiodetermination satellite service." This footnote has since been interpreted by the International Frequency Registration Board (IFRB) to mean that radio astronomy has higher status in Regions 1 and 3 than the RDSS, even in the countries where the allocation status of the RDSS has been raised to primary by RR 734B. This protection was adopted largely as a result of the efforts of the U.K. delegation. In Region 2, the relative status of radio astronomy and the RDSS is more complex. In the U.S., radio astronomy operations had been given limited protection by the FCC ruling. The effectiveness of this protection was discussed by Thompson (1988).

\section{AERONAUTICAL PUBLIC CORRESPONDENCE}

Aeronautical Public Correspondence (APC) is an application of the aeronautical mobile or the aeronautical mobile satellite services. Its purpose is to make voice, and possibly data, communications available to aircraft passengers and to provide an interconnection with the public telephone network. The service may be provided by relaying the message first to a satellite and subsequently to a ground station tied into the telephone network. Alternately, the message may be transmitted directly from the aircraft to a network of ground stations linked to the telephone network. System characteristics and requirements differ in the two cases. For example, terrestrial APC is feasible only over land and coastal areas, while satellite APC may be provided from any point covered by the footprint of the provider system. In the U.S. and Canada, a terrestrial APC system has been operating since 1984 on an experimental basis in the $800 \mathrm{MHz}$ region of the spectrum. A final decision on allocating spectrum to the service and licensing it is, however, still pending. While, in principle, terrestrial- and satellite-based APC systems may complement each other, there has been some preference in the U.S. to a satellite APC system. On the other hand, many European countries expressed preference for a combined terrestrialsatellite APC system. In particular, they proposed that the $1559-1626.5 \mathrm{MHz}$ bands be used by the aeronautical mobile service to supplement or extend the 
aeronautical mobile satellite use of the same bands. The mixed use of the bands was opposed by the U.S. and a large number of other countries. As a compromise, the WARC allocated the bands $1593-1594 \mathrm{MHz}$ and 1625.5-1626.5 $\mathrm{MHz}$ to the aeronautical mobile service (on a primary basis in Region 1 and on a secondary basis in Regions 2 and 3 ) to provide for preoperational and experimental APC systems. The first band was allocated to ground-to-aircraft and the second to aircraft-to-ground transmissions. In addition WARC MOB-87 adopted Recommendation COM $4 / \mathrm{H}$, calling on the CCIR to identify technically-preferred alternative frequency bands for a future worldwide terrestrial APC system. The Recommendation also invited the CCIR to develop sharing criteria with services in the same and adjacent bands.

\section{MOBILE SATELLITE SERVICE}

Satellite communications offer significant advantages for mobile users. They allow communications over wide areas and with sites that are difficult or impossible to reach otherwise. The 1979 WARC allocated spectrum to the maritime, aeronautical, and generic mobile satellite services, and the ability to provide these services existed for over a decade. To date, however, only the maritime mobile satellite service (MMSS) has been implemented. Possible applications of the land mobile satellite service (LMSS) include rural telephony, mobile telephony (e.g. from railways), paging and dispatch services, emergency search and rescue services, etc. The 1979 WARC allocated the 1646.5-1660.5 $\mathrm{MHz}$ frequency range to the Aeronautical Mobile Satellite Service(R) (AMSS(R)) for transmissions in the Earth-to-space direction. A small portion of this spectrum, the band $1660-1660.5 \mathrm{MHz}$, was also allocated to the Radio Astronomy Service (RAS) on a shared, primary basis. Radio astronomers use this band to observe the redshifted $1665 \mathrm{MHz}$ and the highly redshifted $1667 \mathrm{MHz}$ $\mathrm{OH}$ lines. ITU regulations limit AMSS(R) communications to matters related to safety and regularity of flight. Due to this limitation, to date no AMSS(R) system has been implemented because a system which transmits safety messages only is not considered economically viable. Consequently, sharing with the AMSS(R) posed no problems for radio astronomers.

At WARC MOB-87, the U.S. and a number of other countries (Australia, Canada, India, Japan, and Mexico) made proposals to reallocate the AMSS(R) bands to the generic Mobile Satellite Service (MSS), except for the half MHz shared with radio astronomy. Such a reallocation would allow mobile satellite systems to come into being by exploiting a variety of services. In addition to those services already provided by the MMSS, those provided under the LMSS, the AMSS(R), as well as the APC could also be offered. The proposals of the other countries favoring a generic MSS allocation did, however, include the reallocation of the $1660-1660.5 \mathrm{MHz}$ band along with the rest of the AMSS(R) bands. On the other hand, reallocation of any portion of the AMSS(R) spectrum was strongly opposed by the International Civil Aviation Organization (ICAO) and by a large number of countries as well. ICAO, along with these countries, would like to see the creation of a satellite system that provides all aeronautical services, including APC, and other nonsafety communications.

Short of an exclusive allocation for radio astronomy (proposed, but rejected at the 1979 WARC), all other alternatives present some problems for radio 
astronomers. Under the plan presented by the U.S., the status of the band would have been unchanged and, therefore, could have been used only to provide safety-of-life and regularity-of-flight communications. The half $\mathrm{MHz}$ band would have been insufficient to establish an independent service and could, therefore, be used only to provide AMSS(R) as an extension of other services. In such a case, accommodations between the AMSS(R) and the RAS could have been sought by geographical sharing (e.g., by making use of the band over the high seas). In case of a reallocation of the AMSS(R) bands, this option appeared to be the preferred alternative for radio astronomy. The other two alternatives would have had a large impact on radio astronomy by allowing all kinds of communications traffic in the band.

The MSS allocation issue was the most controversial one of the Conference and was not resolved until the very last hours. After lengthy and complex negotiations, a compromise, bearing little resemblance to any of the above three alternatives, was worked out. The $1660-1660.5 \mathrm{MHz}$ band was reallocated to the LMSS (Earth-to-space direction) as part of a 4-MHz-wide band (1656.5-1660.5 $\mathrm{MHz}$ ). In addition, WARC MOB-87 added a footnote (RR 730A) allowing administrations to authorize aircraft earth stations and ship earth stations to communicate with space stations in the LMSS. The rest of the AMSS(R) band was not reallocated, but a footnote ( $R R$ 729B) allows administrations to authorize public correspondence in these bands.

The impact of these decisions on radio astronomy remains to be seen. The RAS, which has primary status in the $1660-1660.5 \mathrm{MHz}$ band, may certainly share with the LMSS provided appropriate geographical sharing criteria are established. Sharing with rural radiotelephony at sites which are at a large enough distance from radio astronomy observatories is one possibility, and there are some others. Such solutions are feasible in large countries, such as the U.S., where geographical sharing is possible. Sharing with aircraft earth stations, as authorized by footnote $730 \mathrm{~A}$, is much more difficult. It may, in fact, be possible only over the high seas or in certain areas of the world far from radio observatories making $\mathrm{OH}$ observations.

Clearly, the $4 \mathrm{MHz}$ allocated to the LMSS is not sufficient to establish large, commercially-viable satellite systems. Resolution COM4/14 resolved to limit mobile satellite systems to national service only except in those cases where administrations agree to multinational service. The same Resolution invited the CCIR, the ICAO, and interested international organizations to study the technical and operational characteristics of future mobile satellite systems. Further, it recommended that the ITU Plenipotentiary Conference convene a World Administrative Radio Conference to review allocations in the $1-3 \mathrm{GHz}$ range with a view to provide the necessary spectrum for mobile satellite systems.

\section{FUTURE WARCS}

As anticipated, WARC MOB-87 could satisfy only partially the spectrum requirements of the many new services proposed, particularly those in the area of satellite communications. The Conference recommended that the 1989 Plenipotentiary Conference take appropriate steps to convene a WARC, no later than 1992, in order to revise the Table of Frequency Allocations in the approximate range $1.3 \mathrm{GHz}$ with a view to provide sufficient spectrum to the 
Mobile Satellite Service. In addition, the Conference noted the needs of a number of proposed or planned mobile communication systems and instructed the CCIR and other competent bodies to pursue further studies of their requirements and characteristics. Terrestrial APC systems fall in this category (Rec.Com4/H). Studies related to terrestrial APC systems are currently being carried out by CCIR Interim Working Party 8/14 (IWP 8/14) which deals with the requirements and characteristics of the MSS. Another system which was recommended for further study (Rec Com4/G) is the Future Public Land Mobile Telecommunication System (FPLMTS). This system, which may have a bandwidth requirements as large as $800 \mathrm{MHz}$ of shared spectrum in the 500-3000 $\mathrm{MHz}$ range, is currently being studied by CCIR IWP8/13.

The World Administrative Radio Conference on the Use of the Geostationary Orbit, held in September 1988 (WARC ORB-88), passed similar resolutions instructing the 1989 Plenipotentiary Conference to convene a WARC (or WARCs) to provide spectrum for the Broadcasting Satellite Service(Sound) (BSS(Sound)) in the 500-3000 MHz range (Res. Com5/1) and for High Definition Television (HDTV) in the 11.7-12.7 and 12.7-23 GHz bands (Res. Com5/3). A number of similar resolutions and recommendations were, of course, on the books even before WARC MOB-87. Table 1 shows the major pressures now existing on the radio spectrum as reflected by Conference resolutions and recommendations in the $3 \mathrm{MHz}$ to $30 \mathrm{GHz}$ range approximately. Two resolutions that call for a reduction in spectrum allocation to the aeronautical radionavigation service, thus conceivably making some spectrum available, are summarized in Table 2.

Given the intense pressures, it is highly likely that a WARC dealing with all services will be convened by 1992 by the ITU. This decision will have to be made by the Plenipotentiary Conference which will be held in Nice in May-June 1989. The real question appears to be not if such a WARC will be convened but its terms of reference.

\section{SUMMARY}

WARC MOB-87 had limited potential impact on radio astronomy allocations since it was competent to make changes only in the status of bands allocated to the mobile services. In shared bands, a further limitation was imposed by the minimum impact requirement. In the neighborhood of the 1612 $\mathrm{MHz} \mathrm{OH}$ line, spectrum was allocated to the RDSS, but strong protection was afforded to radio astronomy in Regions 1 and 3, and the situation in Region 2 did not change much as a result of the Conference. In the U.S., the situation remained the same as before the Conference, and Argentina (the other Region 2 country where observations of the $1612 \mathrm{MHz}$ line had been carried out) did not recognize the Conference action. The terrestrial APC allocations had no impact on radio astronomy allocations. Radio astronomers do, however, face a worsening interference situation in the $1660-1660.5 \mathrm{MHz}$ band as a result of the Conference. This outcome could possibly have been avoided if radio astronomers had contacted their national telecommunications administrations and voiced their need to retain the band.

To prevent further deterioration of the interference situation faced by many radio astronomy observatories, and to prevent the loss of radio astronomy 
allocations at the next WARC, an effort must be made to convince the public of the need for the continued protection of the passive bands and to develop criteria for sharing the less-important or less-used bands. A crucial step in this process is the establishment of close contacts with national telecommunication administrations. It is desirable that radio astronomers participate in WARCs as well as in the work of the CCIR. It is certainly desirable that radio astronomers be represented on national delegations. This, however, is not always possible due to financial constraints and sometimes also because of limitations on the size of national delegations. Finally, it is essential that radio astronomers be represented at WARCs and in the CCIR by the Inter Union Commission on the Allocation of Frequencies (IUCAF). As an international organization, IUCAF may be privy to discussions from which national delegates are sometimes excluded. Further, IUCAF is not bound by national positions, unlike astronomers who participate as members of national delegations.

\section{REFERENCES}

Rothblatt, M. A., 1987, "Radiodetermination Satellite Services and Standards," Artech House, Noorwood, MA.

Thompson, A.R., 1988, "The Feasibility of Sharing Between the Radio Astronomy Service and the Radiodetermination Satellite Service in the $1612 \mathrm{MHz}$ Band," These Proceedings.

\section{TABLE I MAJOR PRESSURES ON THE RADIO SPECTRUM (3 MHz to $30 \mathrm{GHz}$ )}

$\begin{array}{lll}\begin{array}{l}\text { SPECTRAL } \\ \text { TARGET } \\ \text { RANGE }\end{array} & \text { SERVICE } & \text { PURPOSE } \\ 30-3 \mathrm{MHz} & \text { HFBC } & \begin{array}{l}\text { Provide additional } \\ \text { allocations for high } \\ \text { frequency broadcast }\end{array} \\ 0.5-3 \mathrm{GHz} & \text { MSS } & \begin{array}{l}\text { Provide allocations } \\ \text { for the Future Public } \\ \text { Land Mobile Satellite } \\ \text { System (FPLMS) }\end{array} \\ & & \begin{array}{l}\text { Provide allocations } \\ \text { for Worldwide air-to- } \\ \text { ground Telephone } \\ \text { system }\end{array} \\ & \text { Mobile (Terrestrial } \\ & & \end{array}$

DATE

1992

1992

1992 
1-3 GHz

$2.9-3.1 \mathrm{GHz}$

$9.3-9.5 \mathrm{GHz}$

$10.7-11.7 \mathrm{GHz}$

$12.1-12.7 \mathrm{GHz}$

27.0-27.5 GHz

$11.7-23 \mathrm{GHz}$

$21.4-33 \mathrm{GHz}$
MSS

FSS

BSS

Space

Explor.
Provide allocations

for Generic Mobile

satellite Service

Allocate feeder links

for MSS, RDSS, BSS

(Sound and Television)

HDTV (see below)

Provide allocations

for High Definition $\mathrm{TV}$

Provide allocations

for space activities

(DRS's, space station

links, etc.)
1992

1992

1992

1994

\section{TABLE II SPECTRUM THAT MAY BECOME AVAILABLE}

\begin{tabular}{llc}
$\begin{array}{l}\text { SPECTRAL } \\
\text { RANGE }\end{array}$ & \multicolumn{1}{c}{ SERVICE } & \multicolumn{1}{c}{ PURPOSE } \\
$4.2-4.4 \mathrm{GHz}$ & $\begin{array}{l}\text { Aeronaut. } \\
\text { Radionav. }\end{array}$ & Some Reduction in spectrum \\
$5.0-5.25 \mathrm{GHz}$ & $\begin{array}{c}\text { Aeronaut. } \\
\text { Radionav. }\end{array}$ & Some Spectrum to be shared
\end{tabular}

